\title{
Separation of Ovotransferrin from Egg White by Immobilized Metal Affinity Chromatography
}

\author{
S. A. Al-Mashikhi and Shuryo NaKaI \\ Depertment of Food Science, University of British Columbia, \\ Vancouver, B.C. Canada, V6T $2 A 2$
}

Received April 16, 1987

\begin{abstract}
Immobilized metal affinity chromatography (IMAC) was used to separate ovotransferrin (OVT) by a single chromatographic step. Ovotransferrin was bound strongly to immobilized copper ions, while other components of egg white passed through the column. Using acidic $\mathrm{pH}$ and /or a strong competing solute, imidazole, ovotransferrin was recovered in $94 \sim 98 \%$ pure form as indicated by SDS-polyacrylamide gel electrophoresis and immunoelectrophoresis. The elution profiles from the IMAC column indicated the presence of two forms of ovotransferrin. The capacity of the IMAC column was $20 \mathrm{mg} \mathrm{OVT} / \mathrm{ml}$ copper loaded gel. Saturation of the metal binding sites of ovotransferrin with $\mathrm{Fe}^{2+}$ and $\mathrm{Cu}^{2+}$ did not interfere with the binding of ovotransferrin to the IMAC column. However, modification of the histidine residues in ovotransferrin with diethyl pyrocarbonate almost completely destroyed the binding to the IMAC column.
\end{abstract}

Ovotransferrin, also called conalbumin, is a glycoprotein with a molecular weight of about 76,000 and contains no free sulfhydryl groups or phosphorus. The protein moieties of ovotransferrin of egg white and transferrin of chicken blood serum are identical, but the carbohydrate prosthetic groups are different. ${ }^{1)}$

Shade and Caroline reported for the first time growth inhibition of $E$. coli and other bacterial species caused by ovotransferrin ${ }^{2)}$ as well as by serum transferrin. ${ }^{3)}$ This antibacterial effect was destroyed by the addtition of $\mathrm{Fe}^{3+}$ which saturated the iron binding sites of the proteins. ${ }^{4)}$

Valenti et al. ${ }^{5)}$ concluded that the antimicrobial activity of hen's ovotransferrin was quantitatively and qualitatively similar to that of human lactoferrin. These proteins demonstrated a similar protective effect on experimentally-induced bacterial infections in newborn guinea pigs. These observations have led to the concept of "nutritional immunity". ${ }^{6}$ )

A greater resistance against enterobacterial infection of human infants fed with breast milk than those fed with artificial formula is well documented. This has been attributed, to a great extent, to the presence of a large quantity of lactoferrin in human milk compared to cow's milk. ${ }^{7)}$ The similarities in structure and biological activity between ovotransferrin and lactoferrin justify the antimicrobial effect of ovotransferrin added to infant formula. ${ }^{5)}$ Ovotransferrin did not sensitize ovotransferrin-fed infants. ${ }^{8)}$

To invstigate the physiological role of ovotransferrin, it is necessary to have a pure preparation of the protein. The methods most frequently used are based on salt precipitation and ion exchange..$^{9 \sim 12}$ These methods are labor-intensive and difficult to mechanize. We have used the metal-chelate affinity chromatography developed by Porath et al. ${ }^{13)}$ for isolation of immunoglobulins and transferrin from blood, ${ }^{14)}$ based on the property of certain proteins to bind transition metals.

The objective of this paper was to apply immobilized metal affinity chromatography to the purification of ovotransferrin from egg white.

\section{MATERIALS AND METHODS}

Eggs were obtained from the University of British 
Columbia experimental farm. To obtain a homogeneous and less viscous sample with suitable flow properties, the separated egg whites were blended $(2000 \sim 2500 \mathrm{rpm}$, $7 \sim 10 \mathrm{sec}$ ) in a Lourdes MM-1A MultiMixer (Lourdes Instrument Corporation, Old Bethpage, NY) as reported by Li-Chan et al. ${ }^{15)}$ Standard ovotransferrin, ovalbumin, and diethyl pyrocarbonate (DEP) were purchased from Sigma Chemical Company (St. Louis, MO). All other reagents were of analytical grade.

Synthesis of chelating gel. Sepharose 6B (Pharmacia [Canada] Dorval, Quebec) was activated and cross-linked using 1,4-butanediol diglycidyl ether (BGE) by the method of Sundberg and Porath: ${ }^{16)}$ iminodiacetic acid (IDA) was coupled to the activated gel using the procedure of Porath and $\operatorname{Olin}^{17)}$ for the preparation of IDA-Sepharose 6B.

Chromatography. All experiments were done at room temperature unless otherwise stated. IDA-BGE Sepharose $6 \mathrm{~B}$ was packed into a column $(1.4 \times 7.0 \mathrm{~cm})$. The upper half of the column was saturated with copper ions by applying $0.05 \mathrm{M} \mathrm{CuCl}_{2}$ as indicated by blue color development, then washing with at least two bed volumes of the starting buffer $(0.05 \mathrm{M}$ Tris-acetate $/ 0.5 \mathrm{M} \mathrm{NaCl}, \mathrm{pH}$ 8.2). After sample application, the unbound material was washed with the starting buffer; the bound proteins were then eluted with $0.05 \mathrm{M}$ acetate-Tris/ $0.5 \mathrm{M} \mathrm{NaCl}, \mathrm{pH} 4.0$ (see figures for details).

SDS-polyacrylamide gel electrophoresis. Sodium dodecyl sulfate-polyacrylamide gel electrophoresis (SDSPAGE) was done in a vertical slab unit (electrophoresis apparatus SJ-1060 SDH, Atto Co., Tokyo) by the method of Laemmli. ${ }^{18)}$ The stacking gel and separating gel were $3 \%$ (in $0.125 \mathrm{M}$ Tris- $\mathrm{HCl}$ buffer, $\mathrm{pH} 6.8$ ) and $10 \%$ (in $0.375 \mathrm{M}$ Tris- $\mathrm{HCl}$ buffer, $\mathrm{pH} 8.8$ ) polyacrylamide, respectively. Both gels contained $0.2 \%$ SDS. The electrophoresis buffer was $0.025 \mathrm{~m}$ Tris- $0.192 \mathrm{M}$ glycine, $\mathrm{pH} 8.3$, containing $0.1 \%$ SDS. Samples were dissolved in stacking gel buffer containing $5.0 \%$ SDS and $2 \%$ mercaptoethanol, heated for $1.5 \mathrm{~min}$ in a boiling water bath. The electrophoresis was done at $100 \mathrm{~V}$ for $4 \sim 5 \mathrm{hr}$. The staining solution of Weber and Osborn ${ }^{19)}$ was used; that is $0.25 \%$ Coomassie brilliant blue R-250 in acetic acid-methanolwater (1:5:5 in volume). The destaining solution was acetic acid-methanol-water ( $7: 5: 88$ in volume). Bromophenol blue as the tracking dye was used to monitor the progress of sample migration.

Measurement of the capacity of IMAC for ovotransferrin $(O V T)$. A solution $(0.2 \% \mathrm{w} / \mathrm{v})$ of commercial OVT with $\mathrm{A}_{280}$ of approximately 1.94 was passed through a small column $(1.4 \times 7 \mathrm{~cm})$ containing $3 \mathrm{ml}$ copper-loaded chelating Sepharose $6 \mathrm{~B}$ equilibrated with the starting buffer. While the OVT solution was being put on the top of the column, the eluted fractions were continually monitored by measuring $A_{280}$. Saturation of the column (i.e., no further binding of protein) was indicated when the $A_{280}$ of the eluted fractions reached 1.94 . The binding capacity of the copper-loaded gel was calculated as the difference between the amounts of OVT applied and unbound.

After washing off the unbound protein with the starting buffer, the bound proteins were eluted first with $0.05 \mathrm{M}$ acetate-Tris buffer at $\mathrm{pH} 4.0$ containing $0.5 \mathrm{M} \mathrm{NaCl}$, and then with $0.1 \mathrm{M}$ imidazole. The recovery of OVT was calculated as the percentage of eluted protein in bound protein.

Antisera. Antiserum to egg white protein was produced by immunizing adult female New Zealand white rabbits with $1 \sim 10 \mathrm{mg}$ of antigen emulsified in Freund's complete adjuvant (FCA). Immunizations were given in multiple subcutaneous sites, and repeated intravenously in two to six weeks by replacing FCA with phosphate buffered saline, $\mathrm{pH} 7.2$, as a carrier until a satisfactory response was obtained. Serum was tested by double diffusion in gel against egg white proteins as repoted by Garvey et al. ${ }^{20)}$

Preparation of apo, diferric, and dicupric $O V T$. Iron free (apo) OVT was prepared by dialyzing standard OVT first against $0.1 \mathrm{M}$ citric acid, $\mathrm{pH} 2 \sim 3$ for $36 \mathrm{hr}$ at $4{ }^{\circ} \mathrm{C}$, then against deionized water before lyophilization. Diferric OVT was prepared by dialyzing the apo-OVT against $1.7 \mathrm{~mm}$ ferrous ammonium sulfate for $36 \mathrm{hr}$, then excess iron was removed by gel filtration on a Sephadex G-25 column equilibrated with $0.05 \mathrm{M}$ Tris-acetate $/ 0.5 \mathrm{M} \mathrm{NaCl}$, pH 8.2. ${ }^{21)}$ In a similar manner, dicupric OVT was prepared by dialyzing against $0.01 \mathrm{~m}$ cupric chloride.

Histidine modification of $O V T$. Histidine residues of OVT were modified by the method of Rogers et al. ${ }^{22)}$ with modifications. Enough DEP to make the final concentration of $20 \mathrm{mM}$ was added directly to a $50 \mu \mathrm{M}$ OVT solution in $0.05 \mathrm{M}$ phosphate buffer, $\mathrm{pH} 6.6$, containing $8 \mathrm{~m}$ urea, while stirring. After $20 \mathrm{~min}$ stirring the extent of ethoxyformyl histidine formation was measured by an increase in $A_{240}$ of the reaction solution $\left(E_{240}=5.9 \times 10^{3}\right.$ $\left.1 \mathrm{M}^{-1} \mathrm{~cm}^{-1}\right){ }^{23)}$ The purity of DEP used was examined by the method of Holbrook and Ingram. ${ }^{24)}$

\section{RESULTS AND DISCUSSION}

\section{Immobilized metal affinity chromatography of egg white}

Transition metals form complexes with compounds rich in electrons. These compounds may be aromatic or heterocyclic, including proteins, due to their contents of Cys, His, and Tyr. However, the binding of these groups to metal ions depends on the availability of these groups or the topography of the protein molecule. ${ }^{25)}$ 


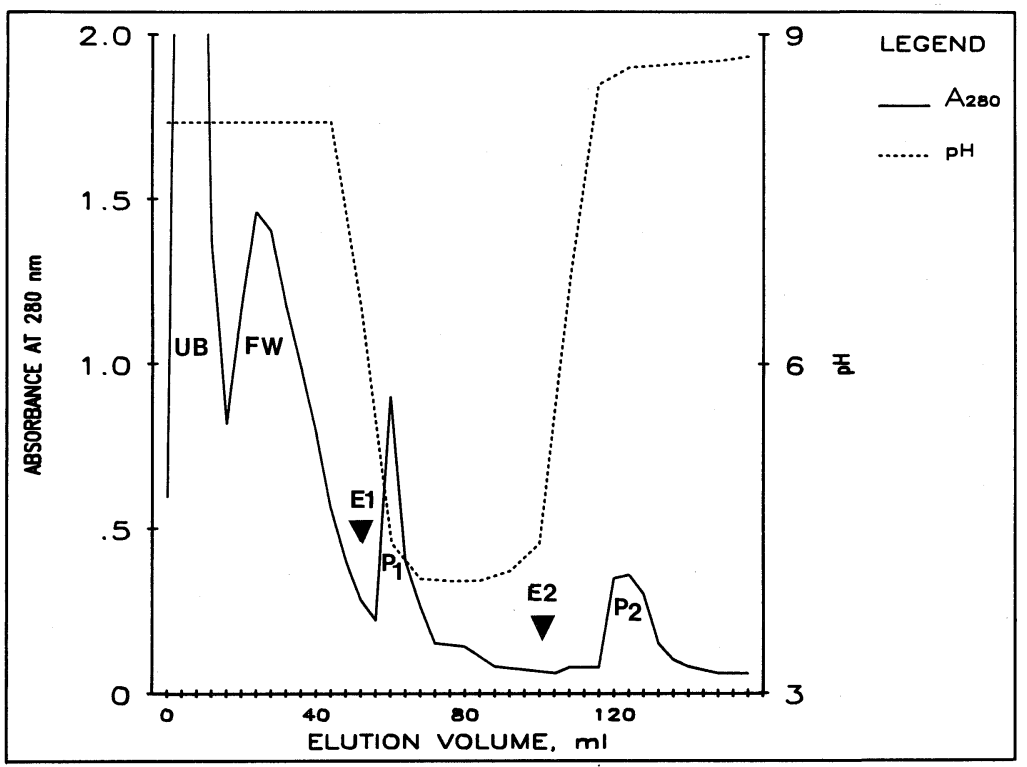

FIG. 1. Immobilized Metal Affinity Chromatography of Egg White.

Two $\mathrm{ml}$ of undiluted blended egg white was passed through a $\mathrm{Cu}$-loaded Sepharose 6B IMAC column $(7 \times 1.4 \mathrm{~cm})$. UB, unbound proteins; FW, fraction eluted with washing step; E1, elution with starting buffer, $\mathrm{pH} 4.0$; P1, fraction eluted with E1; E2, elution with $0.1 \mathrm{M}$ imidazole; P2, fraction eluted with E2.

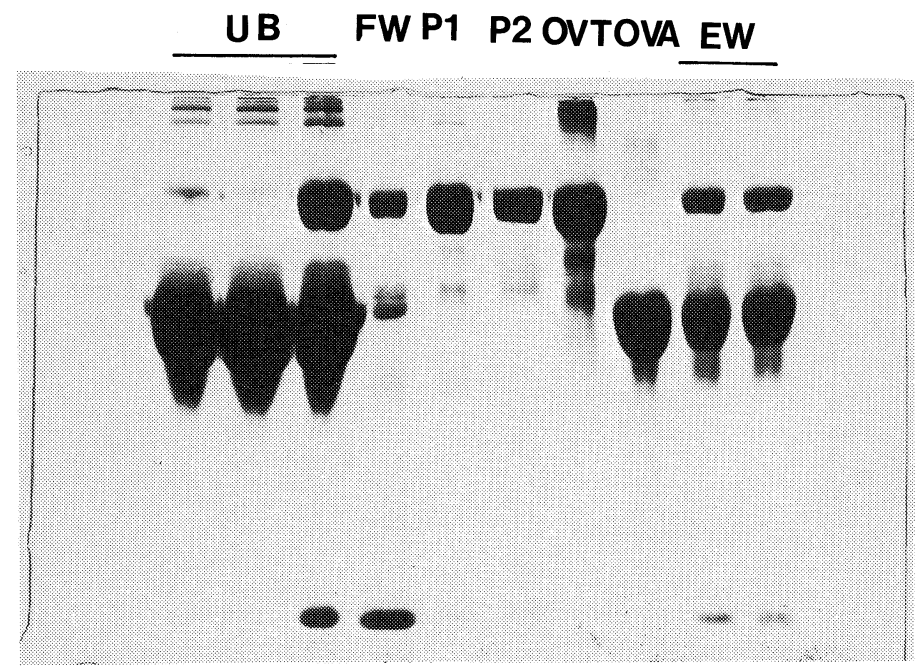

FIG. 2. SDS-PAGE of Fractions of Egg White Eluted under Conditions Shown in Fig. 1.

OVT, standard ovotransferrin; OVA, standard ovalbumin; EW, egg white.

Figure 1 represents the elution profile of undiluted, blended egg white on copper-loaded Sepharose 6B. As indicated by SDS-PAGE (Fig. 2), at an early stage the unbound material was mainly ovalbumin, but at a later stage, most of the egg white proteins passed through, suggesting that the column had reached its saturation point. During the washing step, another peak (FW) appears in the eluant. which appears to be a mixturs of ovotransferrin and lysozyme. The bound material eluted at $\mathrm{pH} 4.0$ (P1) was $98 \%$ pure ovotransferrin, 
by densitometry. The protein eluted with $0.1 \mathrm{M}$ imidazole (P2) was also $94 \%$ pure ovotransferrin. These purity values were higher than the purity of $72 \%$ measured for the standard ovotransferrin. Immunoelectrophoresis against anti-egg white proteins antiserum indicates that the ovotransferrin fraction (P1) obtained by IMAC is fairly pure and is free from contaminants which appeared in the commercial ovotransferrin (Fig. 3).

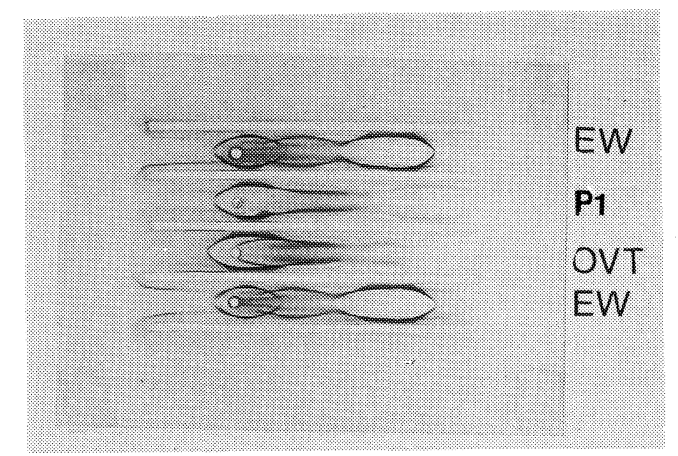

FIG. 3. Immunoelectrophoresis against Anti Whole Egg White Antiserum of Ovotransferrin Fraction (P1) Prepared by Our Method as Compared to Commercial Ovotransferrin (OVT), and Egg White (EW).
Contaminating proteins appearing on the electrophoretogram (Fig. 2) could be ovoinhibitor, judging from the molecular weight differences: 49,000 compared to 76,000 and 44,500 for ovotransferrin and ovalbumin, respectively. ${ }^{1)}$ Therefore, gel filtration chromatography may be useful for further purification of the ovotransferrin fraction separated by IMAC.

\section{Capacity of IMAC for $O V T$}

Figure 4 shows the $A_{280}$ profile of the eluted fractions from $0.2 \%$ commercial OVT solution $\left(A_{280}=1.94\right)$ in measuring the capacity of the copper-loaded chelating sepharose 6B. Saturation of the column was reached at an elution volume of about $60 \mathrm{ml}$ when the $A_{280}$ of the eluted fraction reached 1.94, indicating that no more protein was adsorbed from the OVT solution put on. At this point, the capacity for OVT was calculated to be approximately $20 \mathrm{mg}$ OVT/ml copper-loaded gel. Subsequent elution with buffer at $\mathrm{pH} 4.0$ (P1) and with $0.1 \mathrm{M}$ imidazole $(\mathrm{P} 2)$ recovered $65 \%$ and $30 \%$ of the bound OVT, respectively. Thus, the binding capacity of OVT appears to

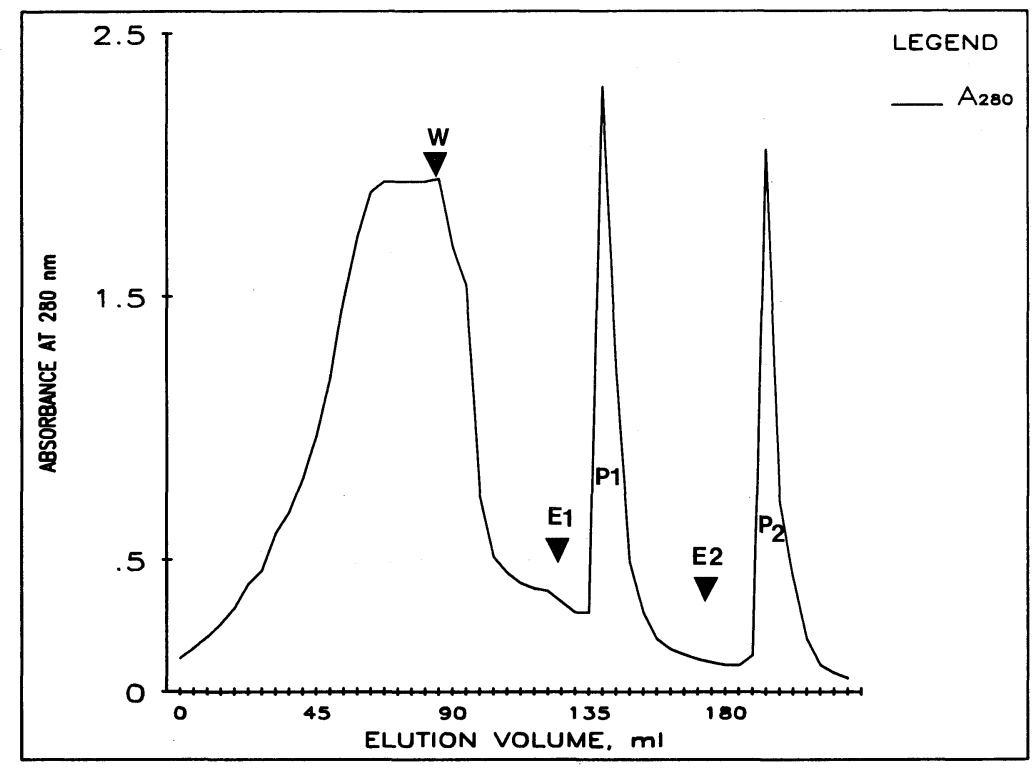

FIG. 4. Saturation Profile of Commercial Ovotransferrin on-Cu-loaded Sepharose 6B IMAC.

The $0.2 \%$ ovotransferrin was passed through $3 \mathrm{ml}$ of a Cu-loaded column $(7 \times 1.4 \mathrm{~cm})$. El, elution with $0.05 \mathrm{M}$ acetate-Tris $/ 0.5 \mathrm{M} \mathrm{NaCl}, \mathrm{pH} 4.0$; E2, elution with $0.1 \mathrm{~m}$ immidazole. 
be lower than that reported by Lonnerdal et $a l .{ }^{26)}$ for human lactoferrin (Lf), which is $70 \mathrm{mg} \mathrm{Lf} / \mathrm{ml}$ gel containing 50 moles of copper ions.

The desorption of OVT in two steps may indicate the presence of at least two forms of OVT. One form can be eluted by lowering the $\mathrm{pH}$. The acidity weakens the binding of protein with the metal ion by protonation of the protein electron donor groups which are responsible for binding with the metal ions. The second form can be eluted by using a strong competitor, imidazole. Imidazole can efficiently compete with exposed His groups on the protein for the metal binding. As reported by Sulkowski, ${ }^{25)}$ the presence of one histidine residue is sufficient for retention while the presence of 2 or 3 His results in multipoint attachment to IDA-Cu gel and a stronger retention. The two forms of conalbumin reported by Clark et al. ${ }^{27)}$ and Feeney et al. ${ }^{28)}$ were discussed by Powrie and Nakai. ${ }^{1)}$ Rogers et $a .^{22)}$ reported two forms of histidine in O'VT, one reactive and the other DEP-nonreactive.

\section{Mechanism of OVT Separation by IMAC}

The binding of OVT to metal-chelate gel is believed to be the result of the ability of electron-rich groups such as histidine and tryptophan to replace weakly bonded water or buffer in the metal complex. ${ }^{29}$ ) The stability of the binding even in $1 \mathrm{M} \mathrm{NaCl}$ would rule out the possibility of ionic interaction being the principle force in the interaction. To find whether the metal binding ability of OVT has any role in the mechanism of OVT separated by IMAC, metal bound OVT was put on the IMAC column. Figure 5 represents the elution profile of metal free OVT (apo-OVT), and ferric and copper-saturated OVT from the IMAC column. Evidently, an iron- or copper-containing OVT was adsorbed on a $\mathrm{Cu}$-chelate gel and subsequently eluted. Figure 5 also shows that metal-saturated OVT can bind with the IMAC column as strongly as the apo-form of OVT. Before and after chromatography of $\mathrm{Fe}-\mathrm{OVT}$ and $\mathrm{Cu}-\mathrm{OVT}$, the protein contains two atoms of $\mathrm{Fe}^{3+}$ and $\mathrm{Cu}^{2+}$ per molecule, respectively. After addition of an excess of $\mathrm{Fe}^{3+}$ or $\mathrm{Cu}^{2+}$ and subsequent dial-

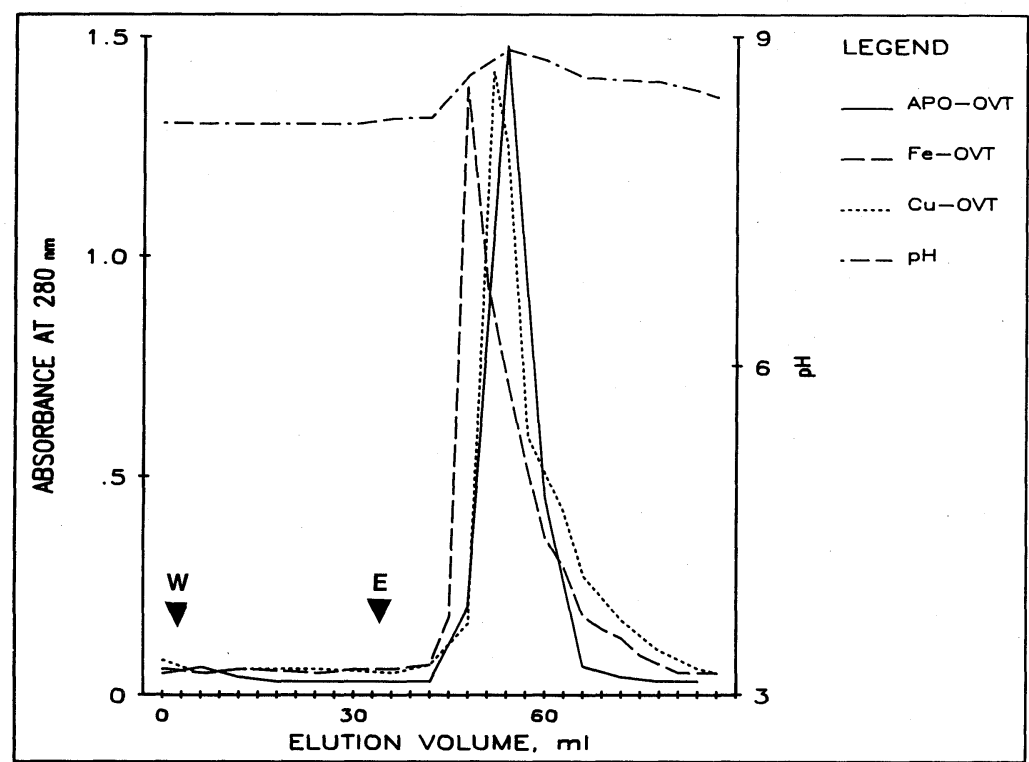

FIG. 5. Immobilized Metal Affinity Chromatography of Apo-ovotransferrin (APO-OVT), $\mathrm{Fe}-$ Ovotransferrin (Fe-OVT) and $\mathrm{Cu}-$ Ovotransferrin $(\mathrm{Cu}-\mathrm{OVT})$.

Three $\mathrm{ml}(8 \mathrm{mg} / \mathrm{ml})$ was put on a Cu-loaded Sepharose 6B IMAC $(7 \times 1.4 \mathrm{~cm})$ after equilibration with $0.05 \mathrm{M}$ Tris-acetate $/ 0.5 \mathrm{M} \mathrm{NaCl}, \mathrm{pH} 8.2$. W, washing with the equilibrating buffer; E, elution with $0.01 \mathrm{M}$ imidazole; flow rate was $30 \mathrm{ml} / \mathrm{hr}$. 


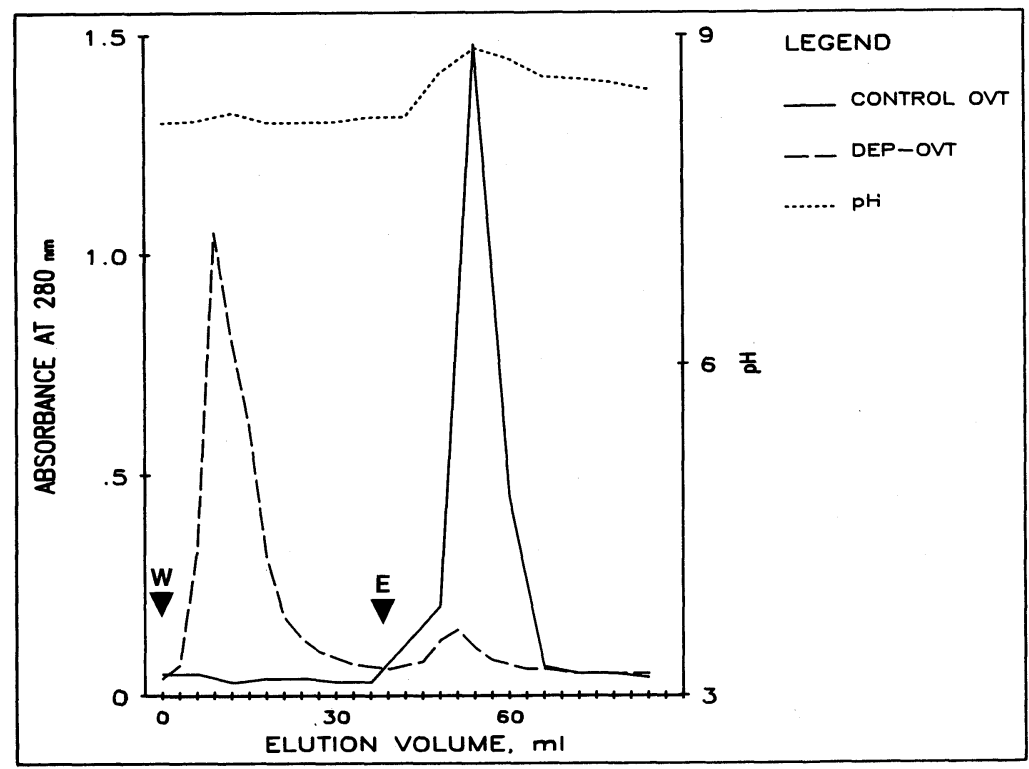

FIG. 6. Immobilized Metal Affinity Chromatography of Control Ovotransferrin and Diethyl Pyrocarbonate Treated Ovotransferrin (DEP-OVT).

Three $\mathrm{ml}(8 \mathrm{mg} / \mathrm{ml})$ was put on a Cu-loaded Sepharose $6 \mathrm{~B}$ column $(7 \times 1.4 \mathrm{~cm})$ after equilibration with $0.05 \mathrm{M}$ Tris-acetate $/ 0.5 \mathrm{M} \mathrm{NaCl}, \mathrm{pH} 8.2$. W, washing with the equilibrating buffer; E, elution with $0.01 \mathrm{M}$ imidazole; flow rate was $30 \mathrm{ml} / \mathrm{hr}$.

ysis, OVT has two bound metal atoms per mole of protein. ${ }^{4)}$ However, on $\mathrm{Cu}$-chelate gel, groups exposed on the surface of OVT may have a tendency to bind copper ions.

To investigate if a histidine group was responsible for the copper-chelate gel and OVT interaction, DEP-modified OVT was put on the column. Figure 6 shows the elution profile of OVT before and after histidine group modification by DEP. Without modification, OVT adsorbed strongly to the $\mathrm{Cu}$-chelate gel and no OVT was eluted in the washing step at alkaline pH. Bound OVT could be released by $0.01 \mathrm{~m}$ imidazole. Histidine-modified OVT (DEPOVT) did not bind to $\mathrm{Cu}$-chelate gel and was almost completely eluted in the washing step at alkaline $\mathrm{pH}$. This behavior of DEP-OVT on $\mathrm{Cu}$-chelate gel clearly indicates that modification of 11.7 histidine residues out of 13 histidine residues per mole of OVT drastically inhibited the ability of the protein to bind to $\mathrm{Cu}$-chelate matrix. Considering that two histidine residues are involved in the metal binding in the $\mathrm{Fe}$ - or $\mathrm{Cu}$-saturated OVT, there are still 11 histidine groups left free to interact with immobilized metal on Sepharose 6B. However, blocking histidine groups would destroy its ability to bind to IMAC column.

In conclusion, this paper describes for the first time a method to separate ovotransferrin from egg white by a single chromatographic step. The specificity and capacity of the IMAC column for ovotransferrin are high, and it should be easy to adapt the method for isolation of ovotransferrin to a larger scale operation. The isolated OVT from egg white may be incorporated in infant formula, since, it has not had sensitizing effects on OVT-treated babies. Del Giacco et al. ${ }^{8)}$ reported that when ovotransferrin-treated milk was fed to 15 babies for 60 days the values of total $\mathrm{IgE}$, as measured by the radioimmunoassay method, remained within the normal range.

\section{REFERENCES}

1) W. D. Powrie and S. Nakai, "Chemistry of Eggs and Egg Products." In Egg Science and Technology, ed. by W. J. Stadelnan and O. J. Cotterill, The AVI 
Publishing Company, Inc., Westport, Connecticut, 1986.

2) A. L. Schade and L. Caroline, Science, 100, 14 (1944).

3) A. L. Schade and L. Caroline, Science, 104, 340 (1946).

4) J. H. Brock, "Transferrins," In Metalloproteins, Part 2: Metal Proteins with Non-redox Roles, ed. by P. M. Harrison, Verlag Chemie, GmbH, Weinheim, 1985.

5) P. Valenti, G. Antonin, C. Von Hunolstein, P. Visca, N. Orsi and E. Antonini, Int. J. Tiss. Reac., 1, 97 (1983).

6) E. D. Weinberg, Am. J. Clin. Nutr., 30, 1485 (1977).

7) V. S. Packard, "Human Milk and Infant Formula," Academic Press Inc., New York, 1982, p.84.

8) G. S. Del Giacco, A. L. Leone and A. Ferlazzo, Int. J. Tiss. Reac., 7, 535 (1985).

9) R. C. Warner and I. Weber, J. Biol. Chem., 191, 173 (1951).

10) J. Williams, Biochem. J., 83, 355 (1962).

11) P. Azari and P. F. Baugh, Arch. Biochem. Biophys., 118, 138 (1967).

12) E. Antonini, U. S. Patent 4,029,711 (1977).

13) J. Porath, J. Carlsson, I. Olsson and G. Belfrage, Nature, 258, 598 (1975).

14) S. A. Al Mashikhi and S. Nakai, sent for publication (1987)

15) E. Li-Chan, S. Nakai, J. Sim, D. B. Bragg and K. V. Lo, J. Food Sci., 51, 1032 (1986).
16) L. Sundberg and J. Porath, J. Chromatogr., 90, 87 (1974).

17) J. Porath and B. Olin, Biochemistry, 22, 1621 (1983).

18) U. K. Laemmli, Nature, 227, 680 (1970).

19) K. Weber and M. Osborn, J. Biol. Chem., 224, 4406 (1969).

20) J. S. Garvey, N. E. Cremer and D. H. Sussdorf, "Methods in Immunology," W. A. Benjamin Inc., Reading, Mass., 1977.

21) M. F. Cole, R. R. Arnold, J. Mestecky, S. Prince, R. Kulhavy and J. R. McGhee, "Microbial Aspects of Dental Caries," Vol. 11, ed. by H. M. Stile, W. J. Loesche and T. C. O'Brien, Information Retrieval Inc., Washington, D. C. and London, 1976.

22) T. B. Rogers, R. A. Gold and R. E. Feeney, Biochemistry, 16, 2299 (1977).

23) J. L. Roosemont, Anal. Biochem., 88, 314 (1978).

24) J. J. Holbrook and V. A. Ingram, Biochem. J., 131, 729 (1973).

25) E. Sulkowski, Trends in Biotechnology, 3, 1 (1985).

26) B. Lonnerdal, J. Carlsson and J. Porath, FEBS Lett., 75, 89 (1977)

27) J. R. Clark, D. T. Osuga and R. E. Feeney, J. Biol. Chem., 238, 3621 (1963).

28) R. E. Feeney, H. Abplanalp, J. J. Clary, D. L. Edward and J. R. Clark, J. Biol. Chem., 238, 1732 (1963).

29) B. Lonnerdal and C. L. Keen, J. Appl. Biochem., 4, 203 (1982). 